\title{
SWMM Modeling of a Rural Watershed in the Lower Coastal Plains of the United States
}

\author{
Kyle P. Moynihan and José G. Vasconcelos
}

\begin{abstract}
The Storm Water Management Model (SWMM) has proven highly effective in modeling urban and suburban watersheds since its conception in 1969. While heavily implemented in the simulation of urban watersheds, its performance in strictly rural watersheds has been less frequently evaluated. Lower Coastal Plain watersheds are prevalent in the southern United States and the description of hydrological processes there is critical to the development of local water resources. This paper presents an ongoing research effort in a rural $2.90 \mathrm{~km}^{2}$ site located in Pittsview, Alabama and owned by Alabama Associated General Contractors. A network of rain gauges, associated with a portable weather station, two monitoring wells and two weirs have been deployed and data is continuously recorded. Collected field data has then been used for initial development efforts of a PCSWMM model that provides representation of the rainfall-runoff processes at the watershed. As more data is obtained with regards to the local water cycle, it is anticipated that the PCSWMM model calibration will improve, which in turn will provide greater confidence in the software's ability to simulation such conditions.
\end{abstract}

Keywords: headwaters, field investigations, undeveloped watershed, SWMM, calibration.

\section{Introduction}

Development of water resources has been an important engineering challenge throughout the United States. A better understanding of the water budget of different natural environments has propelled the development of a number of hydraulic and hydrologic water resource management projects in the past decades (Sun et al. 2002; Davis et al. 2007; Harder et al. 2007; Sun et al. 2010; La Torre Torres et al. 2011). Understanding the differences between hydrologic processes through the array of natural systems is critical to producing more accurate models.

Of particular interest to southern states is the description of hydrologic processes in watersheds located in the lower Coastal Plains (LCP), which constitute a very significant fraction of these watersheds as indicated in Figure 1 (Nagy et al. 2011). LCP watersheds generally are largely influenced by evapotranspiration (ET), which has also been linked to the shallow water tables that are commonly found (Amatya and Trettin 2007; Sun et al. 2010). Water table elevation fluctuates seasonally since it is primarily influenced by regional solar energy and soil characteristics (Sun et al. 2002; La Torre Torres et al. 2011). An interesting question is What are the mechanisms of groundwater and surface water interactions in these LCP watersheds? particularly in the headwater regions where streams are intermittent. One hypothesizes that in these areas the fluctuations of the groundwater table create conditions in which, at times, there is no direct connection between a flowing intermittent stream and the water table. Identification of such losing streams and respective hydrological characterization would be important in the development of water resources, such as the placement and sizing of surface reservoirs.

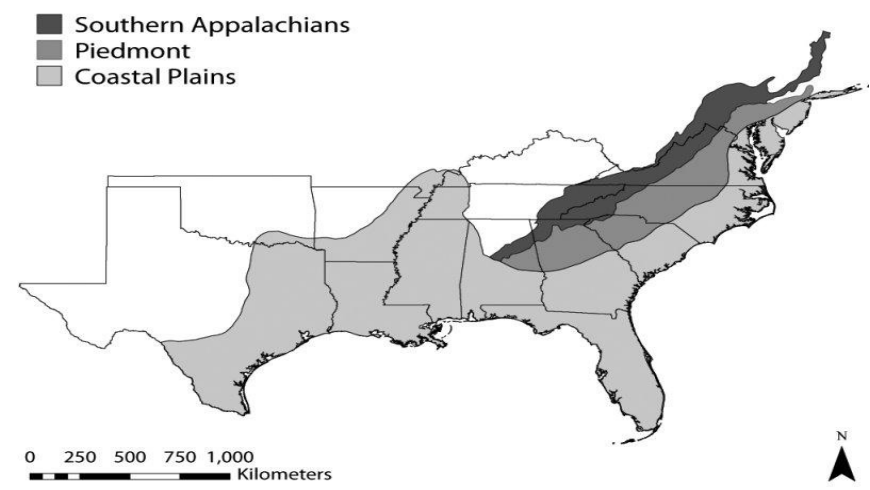

Figure 1 Geological zones of the southeastern United States.

Another important aspect examined is the ability of SWMM models to simulate the hydrological interactions observed in field measurements of undeveloped watersheds. Numerous investigations performed in urban watersheds have demonstrated the ability of a properly calibrated SWMM model to accurately represent rainfall-runoff processes in such environments, including interactions with groundwater, which are implemented with the model's aquifer compartment. SWMM, however, has not been as frequently evaluated in undeveloped watersheds, and to the authors' knowledge previous studies have not included headwaters of a rural LCP watershed. This is the focus of the present work. 


\section{Objectives}

The present work aims to assess the ability of SWMM to represent hydrological processes, particularly surface water and groundwater interactions at the headwaters of a rural LCP watershed. This study was enabled by a 10 y long agreement between Auburn University and the Alabama chapter of the Associated General Contractors of America ( $A G C / A L)$. Still in the first year of investigation, this small $2.90 \mathrm{~km}^{2}$ watershed (henceforth referred to as WS-AGC) is being monitored for several hydrological processes. Site specific continuous monitoring includes rainfall, runoff, climate and shallow groundwater levels. This data is then introduced into PCSWMM and its calibration tools are used to adjust model parameters to conform to observed data.

\section{Methodology}

\subsection{Site Description}

The study site of WS-AGC is located in Pittsview, Alabama $\left(32^{\circ} 9^{\prime} 29.30^{\prime \prime} \mathrm{N}, 85^{\circ} 10^{\prime} 8.09^{\prime \prime} \mathrm{W}\right)$. Covering an area of $2.90 \mathrm{~km}^{2}$ in Russell County, WS-AGC drains a first order intermittent stream positioned at the headwaters of a complex series of tributaries that connect to discharge into Hatchechubbee Creek. The Hatchechubbee Creek then continues south and eventually discharges in the Chattahoochee River just north of Eufaula, Alabama. Figure 2 provides an aerial image of WS-AGC, its stream development predicted from GIS and topographic lines. This area has been used extensively for hunting over the past decades and remains relatively untouched except for a few trails and green fields. The effects of these areas were assumed to have a negligible effect on the hydrology of WS-AGC.

With its location very close to the dividing line between the Piedmont and the LCP regions, the study site possesses characteristics that are peculiar to both regions. With respect to the Piedmont region, the watershed is in an area of many low rolling foothills and contains various patches of clay-like soils. However the area also reflects the LCP region with its low lying central areas. Composition in the LCP environments plays a major role in runoff responses due to the presence of very well to poorly drained soils in low topographic relief areas (La Torre Torres et al. 2011). Similarly to other LCP watersheds, field measurements have indicated that WS-AGC hydrological responses are influenced by evapotranspiration. Observations of this phenomenon show distinct differences between the dry (May to November) and wet (December to April) seasons.
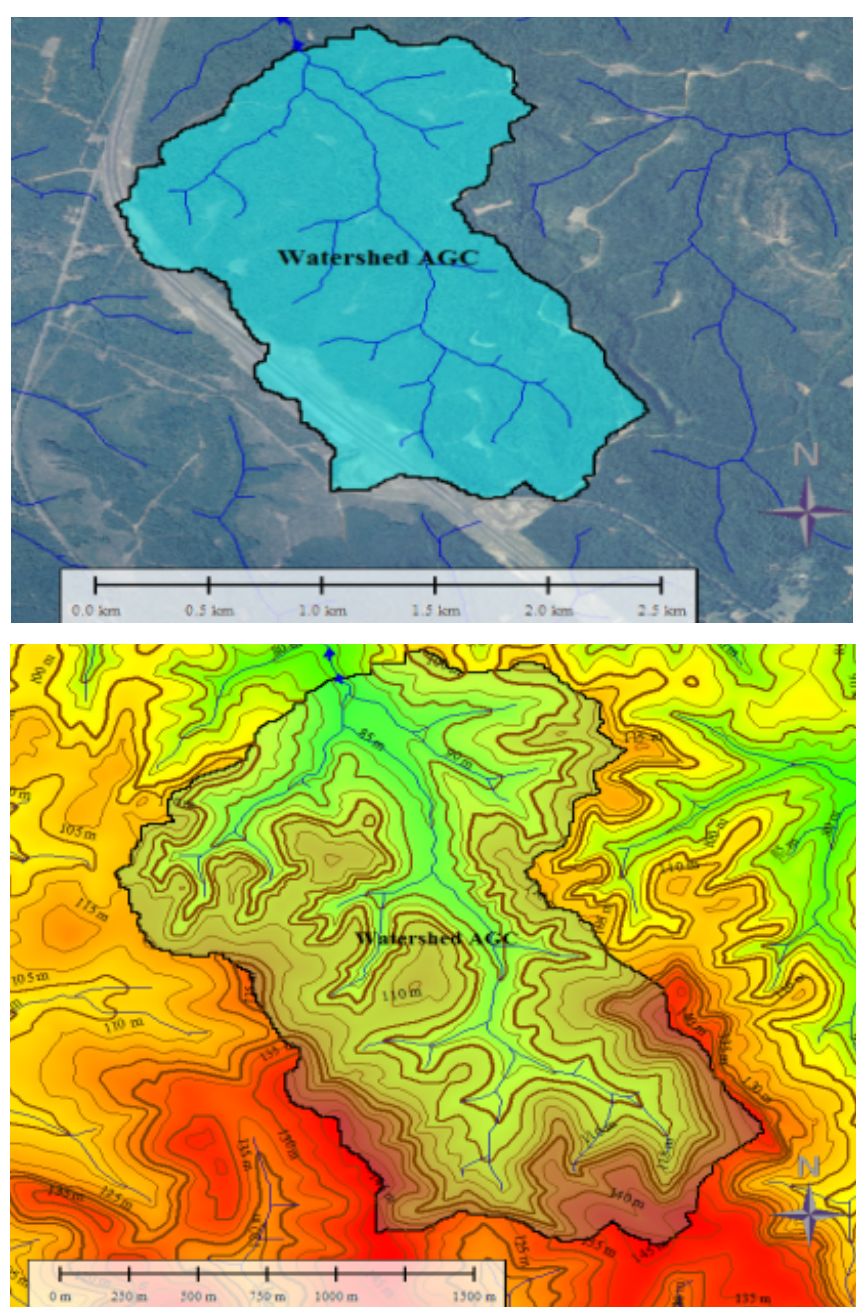

Figure 2 Area view of the WS-AGC with the network of intermittent streams (upper) and respective contour lines (lower).

Finally, the site also displays some hydrological characteristics of uplands regions. Hydrologic processes in upland areas are mainly influenced by steep gradient profiles and hill-slope processes (i.e. interflow, sheetflow and overland flow) and less influenced by soil composition (La Torre Torres et al. 2011). These characteristics provide an opportunity to study a distinct watershed type that to our knowledge has not been examined in the literature (Sun et al. 2002; Czikowsky and Fitzjarrald 2004; Harder et al. 2007; Sun et al. 2010; La Torre Torres et al. 2011; Davis et al. 2007).

WS-AGC has an average slope of approximately $12.4 \%$ and is comprised of several different soil types. After applying the USDA web soil survey tool (http://websoilsurvey.nrcs.usda. gov), the site was determined to consist of mostly Hannon Clay and Trout-Springhill-Luverne (33.3\% and 36.4\% of area of interest, AOI, respectively) as shown in Table 1. The drainage classes consist of a moderately well drained soil (Hannon clay) and well to excessively drained (Trout-Springhill-Luverne). Toward the lower portion of the catchment the soils transition to Kinston 
Mantachie and luka (KMA). KMA possesses the characteristics of a fine sandy loam mixed with clay loam.

Table 1 USGS web soil survey results for WS-AGC study site.

\begin{tabular}{|l|l|r|r|}
\hline \multicolumn{5}{|c|}{ Russell County, Alabama (AL113) } \\
\hline \multicolumn{1}{|c|}{ Map Unit Name } & \multicolumn{1}{c|}{ Acres in AOI } & \multicolumn{1}{c|}{ Percent of AOI } \\
\hline CnB & Conecuh fine sandy loam, 1 to 3 percent slopes & 45.4 & $7.7 \%$ \\
\hline CoC2 & Conecuh loam, 3 to 8 percent slopes, eroded & 2.2 & $0.4 \%$ \\
\hline HnD2 & Hannon clay, 5 to 8 percent slopes, eroded & 196.6 & $33.3 \%$ \\
\hline KMA & $\begin{array}{l}\text { Kinston, Mantachie, and luka soils, 0 to 1 } \\
\text { percent slopes, frequently flooded }\end{array}$ & 27.0 & $4.6 \%$ \\
\hline LnB & Luveme sandy loam, 2 to 5 percent slopes & 52.4 & $8.9 \%$ \\
\hline LSE & $\begin{array}{l}\text { Luveme-Springhill complex, 15 to 25 percent } \\
\text { slopes }\end{array}$ & 51.9 & $8.8 \%$ \\
\hline TSE & $\begin{array}{c}\text { Troup-Springhill-Luveme complex, 10 to 30 } \\
\text { percent slopes }\end{array}$ & 214.9 & $36.4 \%$ \\
\hline Totals for Area of Interest & $\mathbf{5 9 0 . 5}$ & $\mathbf{1 0 0 . 0 \%}$ \\
\hline
\end{tabular}

Near the southern end of WS-AGC a swamp-like collection area exists. Water particularly during the wet season collects here and discharges back into the stream through a series of natural weir-like outlets. As the stream progresses to the north, downstream the channel begins to dramatically increase in size. Originating with channel dimensions of $0.5 \mathrm{~m}$ deep and $1 \mathrm{~m}$ wide, erosive processes caused the progression to dimensions of $3.5 \mathrm{~m}$ deep and $3 \mathrm{~m}$ wide at the base, each with side slopes of approximately 4:1 (vertical:horizonal). The stream bed is lined with a highly erodible sandy soil that has formed many abstractions throughout the channel. At one location the stream channel completely disappears into a large mound of sand and then reappears about $20 \mathrm{~m}$ downstream. Other abstractions have also been created throughout the channel with the large amounts of tree branches and debris that are conveyed downstream.

Vegetative cover in WS-AGC consists of a mixture of slash pine (Pinus elliotii) and loblolly pine (Pinus taeda) throughout, similar to the study site of Harder et al. (2007). The density of the trees begins to increase closer to the stream bed and into the riparian zone. It is here that local bamboo is also mixed in with the pines and becomes very dense in many areas.

\subsection{Field Investigations}

Runoff from WS-AGC is measured with two weirs: a Cipolletti weir and a fully contracted rectangular weir. The Cipolletti weir was constructed at the lowest point in the watershed to measure the total volume of runoff. The stream bed here is approximately $4.6 \mathrm{~m}$ deep and $3 \mathrm{~m}$ wide with irregular side slopes of roughly 4:1 (vertical:horizonal). Stretching across the channel at $3.0 \mathrm{~m}$, the Cipolletti weir has a crest length of $1.1 \mathrm{~m}$ and two $1.8 \mathrm{~m}$ vertical sides, cut at the 4:1 slopes, conforming to the natural slopes. Further upstream, the fully contracted rectangular weir measures flows from approximately $60 \%$ of the contributing watershed area. Stream cross section dimensions there are much smaller, measuring approximately $3.4 \mathrm{~m}$ across with $1.2 \mathrm{~m}$ depth, with irregular side slopes. The weir has crest length of $0.67 \mathrm{~m}$ and height of $1.5 \mathrm{~m}$.

At both locations wooden posts with level loggers (HOBO U20, range $9 \mathrm{~m}$, accuracy $0.5 \mathrm{~cm}$ ) have been positioned at a distance of four times the weir measured head upstream from the crest of the weirs (Dodge 2001). This ensures that the readings are not affected by draw-down associated with the discharge over the weirs. Sensors were placed in the lateral of the posts parallel to the flow. To mark the start of an event $6.1 \mathrm{~cm}$ head is required to consider the flow developed over each weir (Dodge 2001). Readings are continuously measured at $15 \mathrm{~min}$ intervals and a stage discharge relationship specific to each weir has been created.

As mentioned, the streambed has highly erodible soil that has caused many challenges to maintaining the integrity of weirs. Throughout the first year of service, the Cipolletti weir experienced a few large peak discharges which caused minor and major erosion around the side walls. The upstream rectangular weir also experienced lateral seepage caused from the activities of field mice. All of these issues were addressed immediately and damages have been fixed.

Three Onset RG3-M rain gauges have been installed at open grass fields located throughout the watershed. The gauges were strategically placed to divide the watershed into three nearly equal areas. Data at each location is recorded at regular 30 min intervals and is collected at a finer resolution as a rainfall event is occurring. Also located in a green field is a Kestrel 4500 portable weather station. Recording continuously at $30 \mathrm{~min}$ intervals, measurements of various climate information including temperature, barometric pressure, wind speed and humidity are captured. The barometric pressure from this station is critical for locally calibrating the various transducers used for data collection.

Two shallow groundwater wells have been installed next to the rectangular weir. The first well is located approximately $1 \mathrm{~m}$ outside of the stream and reaches a depth of $3 \mathrm{~m}$ below the surface. Located in the center of the stream, $5 \mathrm{~m}$ away, is the second well which has been drilled to the same depth. Both wells were drilled with an $8.25 \mathrm{~cm}$ diameter hand auger allowing for the installation of $3.8 \mathrm{~cm}$ diameter PVC with screens of lengths $61 \mathrm{~cm}$ attached at the ends. A sand pack was placed up to approximately $1 \mathrm{~m}$ to keep fines from entering, and each well was capped with a layer of sodium bentonite. Level loggers (HOBO U20, range 9 $\mathrm{m}$, accuracy $0.5 \mathrm{~cm}$ ) have subsequently been deployed at these wells.

\subsection{SWMM Model Development}

Initially WS-AGC was divided into 7 subcatchments conforming to the local topography. As the model began to be developed, the need for additional discretization to depict diverse geophysical characteristics was recognized. To do this the original seven subcatchments were broken down into smaller sections based on the soil categories predicted from the USGS soil survey, as shown in Figure 3. Subcatchment parameters of area, slope, elevation and percent pervious were all found from a $10 \mathrm{~m}$ DEM and GIS software. On the west edge of WS-AGC, Alabama Highway 431 crosses, accounting for approximately $0.036 \mathrm{~km}^{2}$. At $1.2 \%$ of total watershed area, the impervious road was assumed to have no 
significant influence on the local hydrology and the entire site was considered pervious.

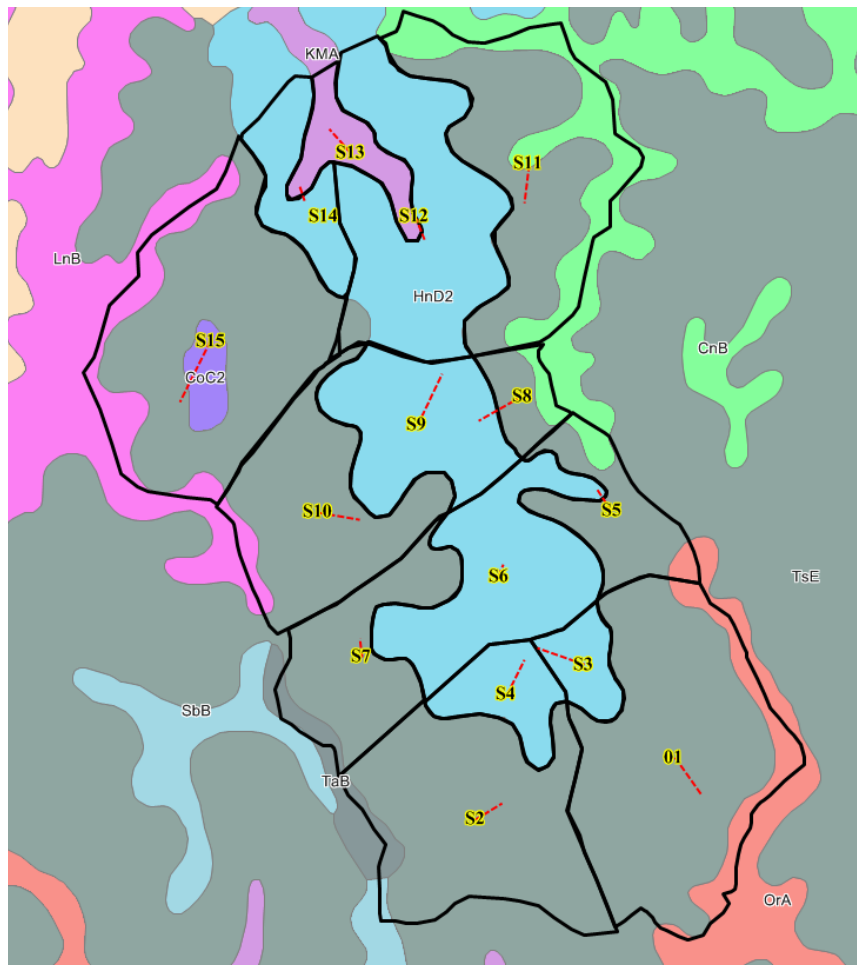

Figure 3 Discretized subcatchments based on topography and soil types for WS AGC.

Geographic information systems (GIS) were used to improve the accuracy of physical input parameters such as subcatchment area, slope, channel lengths and storage reservoirs. Main channel locations and lengths were also established from using a $10 \mathrm{~m}$ DEM and ArcGIS software and confirmed from field investigations. Cross sections were inputted as irregular shapes determined from field survey measurements. These well defined physical inputs provided a good foundation for the initial stages of model development

As model setup continued, estimates of more subjective parameters were necessary. This included Manning roughness (n) for channel and overland flows, depression storage, minimum and maximum infiltration rates, saturated hydraulic conductivity and field capacity. These were estimated based on published values from literature and insights were obtained from several field visits. Results from the USDA/NRCS web soil survey also provided values for subcatchment specific parameters.

Stream beds at the site have many abstractions, vegetal debris, partial obstructions and pooling areas where flow is subjected to large head losses and varying flow conditions. This work used Manning's equation within SWMM to represent flow frictional losses. Thus values of $n$ had to be estimated to represent the complex nature of the channels. Manning's $n$ values used for channels simulation ranged from 0.04 to 0.4 , following ASCE Manual of Practice 60 (Biezer 2007). Such values are consistent with natural channels of irregular sections with pools and having a vegetal characteristic.

Subcatchment estimates for overland flow roughness, depression storage and subcatchment width were mostly obtained with published values and further modeling assumptions. Manning's $n$ for overland flow was estimated as 0.8 , following the McCuen et al. (1996) estimate for dense underbrush in wooded regions. The depression storage value of $7.62 \mathrm{~mm}$ was adopted from the recommended first estimate value in the SWMM 5 User's Manual (Rossman 2005). To calculate each subcatchment width an initial assumption was made that the overland sheet flow would not occur more than 152 m before reaching or transitioning to channelized flow. The two prior values were then slightly altered $( \pm 10 \%)$ during the calibration efforts.

To distinguish individual runoff events from observed data it was assumed the minimum inter-event time as $6 \mathrm{~h}$ and each event's peak discharge must meet a minimum peak flow rate of $0.1 \mathrm{~m}^{3} / \mathrm{s}$; any event below this was not considered in the study. In addition, various events were extended as needed since water levels in the stream fluctuated during the lower portion of the recession curve. This caused readings of water level to dip above and below the required $6.1 \mathrm{~cm}$ head required for flow to fully develop over the weirs (Dodge 2001).

Results from groundwater monitoring in the well positioned at the stream bed, presented in Figure 4, motivated the development of different SWMM models to replicate the hydrological rainfall-runoff response of WS-AGC. Blue bars in the top chart correspond to rainfall intensity, whereas the blue line in the lower chart correspond to the average accumulated rainfall depth measured by the rain gauges deployed in the site. The red lines in both charts correspond to groundwater elevation, and the interruption corresponds to a period of malfunction in the well. Despite of the interruption on the groundwater level measurement, it can be noticed that the initial rain events up to December 19, 2012 have not resulted in any significant change in the groundwater level. The issue with the groundwater well monitoring was solved approximately 30 days later, and at this point the groundwater level was much greater, and at that point connected to the stream. As is shown, even small rain events caused measurable and immediate increase in the groundwater level. This contrasts with the earlier condition, which seems to indicate that the groundwater is disconnected from the stream. Such complexities of interflow and its ability to produce longer recession curves in the wet season made the groundwater module a key addition to SWMM modeling.

While subcatchment modeling parameters were kept the same, three different SWMM models were used represent the aquifer component: a model without any aquifer component; a model with a single aquifer component for the entire WS-AGC; and a model with multiple aquifer components. These models were tested and calibrated focusing on simulation from rain episodes across the transition between dry and wet seasons in 2012. The multi-aquifer configuration also allowed for exfiltration 
Ground Water Level vs Rainfall Intensity

Out of Stream

(Nov 11- Feb 14) 2012-2013

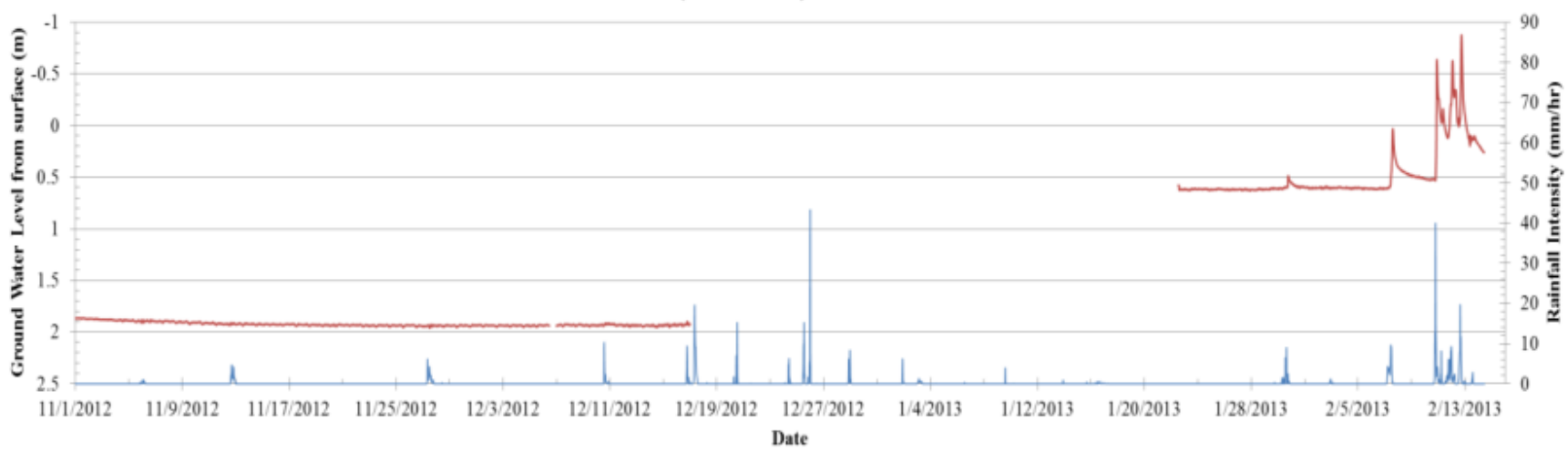

—Water Table Depth (m) —Rainfall Intensity $(\mathrm{mm} / \mathrm{hr}$ )

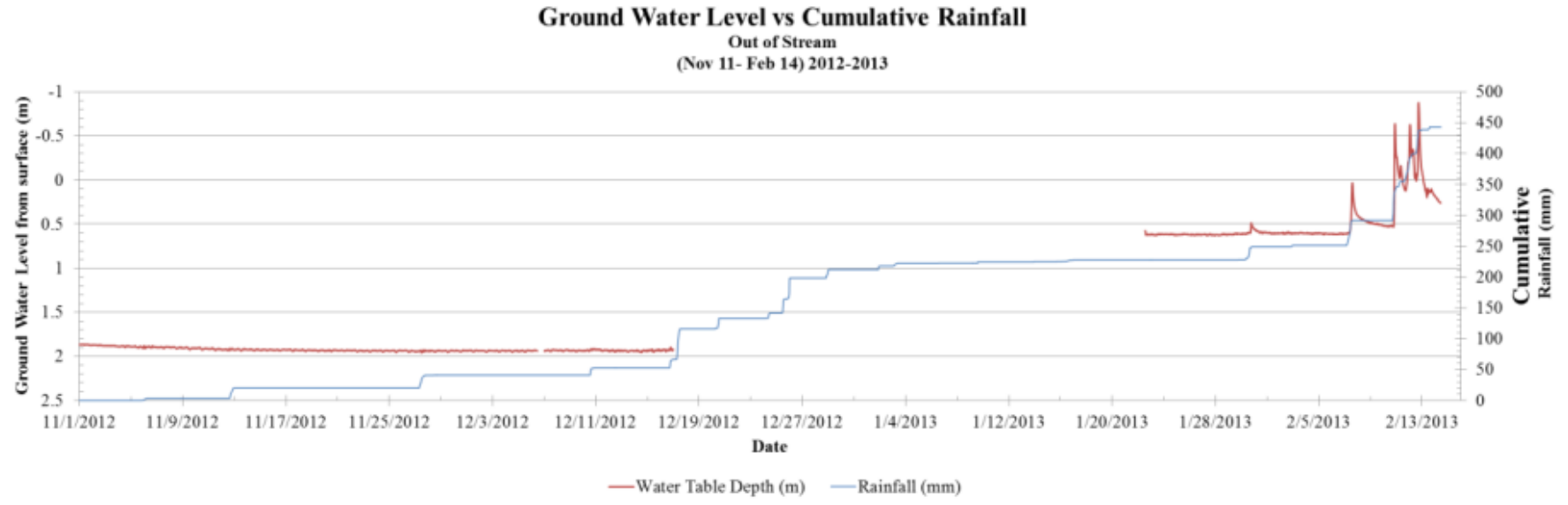

Figure 4 Shallow ground water level relative to the surface for the out of stream observation well.

at several junctions throughout the channel to receive water, whereas the single aquifer configuration allowed for this exfiltration only at the downstream end.

\subsection{Model Calibration}

Calibration was performed for these three SWMM models using eight separate rainfall-runoff events. As mentioned, events were distinguished by inter-event periods $\geq 6 \mathrm{~h}$ and a minimum peak flow rate of $0.1 \mathrm{~m}^{3} / \mathrm{s}$. The calibration between observed and computed rainfall-runoff events was conducted using the sensitivity based radio tuning calibration (SRTC) function of PCSWMM. During this process eight parameters were adjusted, limiting their uncertainty rankings to $\pm 40 \%$, with eight individual runoff events. Following the work of Davis et al. (2007) peak flow rates were examined in addition to flow duration curves for each model configuration. These two comparisons provided calibrated models with respect to peak flow conditions as well as the more challenging issue of flow volumes. The calibration efforts included observed events during the dry season (May to November) and wet season (December to April).

The SRTC tool works by designating uncertainty percent rankings for each parameter of interest. For efficient calibration, first estimates of the model parameters should be as close as possible to the true value (James et al. 2002). Also percent rankings should be limited to $\pm 50 \%$ as an absolute maximum. This will insure that calibration parameters will not become arbitrary values outside of meaningful range for the AOI. Another important aspect to calibration is having the correct number of rainfall-runoff events for the number of parameters of interest. Following ames et al. (2002), the quantity of calibration parameters was limited to the number of individual rainfall-runoff events observed and selected for calibration. In this case eight separate observed rainfall-runoff events were used to calibrate eight parameters. In all events, the hydrograph obtained at the downstream (Cipolletti) weir was used as reference.

Horton's method was selected to model the infiltration at the site. The four main input parameters include maximum 
infiltration rate, minimum infiltration rate, decay constant and drying time. The most sensitive of the four infiltration parameters were the minimum/maximum infiltration rate and the decay constant. Each subcatchment was assigned an average maximum and minimum infiltration rate based on a range found from examining the local soil types. These values were provided from Akan (1993) and are listed below in Table 2. Estimates for decay constants and drying times were made from an average of the range provided by the SWMM 5.0 User's Manual (Rossman 2005). During the early stage of calibration the drying time was found to have minimal effect on the results so it was fixed at the maximum value of $8 \mathrm{~d}$.

Table 2 Maximum and minimum infiltration rates based on soil types (Akan 1993).

\begin{tabular}{lcc}
\hline \multicolumn{1}{c}{ Soil Type } & \multicolumn{2}{c}{ Maximum (Initial) } \\
& (nfiltration \\
(in) & 5.0 & 127 \\
\hline Dry sandy soils with little or no vegetation & 3.0 & 76.2 \\
Dry loam soils with little or no vegetation & 1.0 & 25.4 \\
Dry clay soils with little or no vegetation & 10 & 254 \\
Dry sandy soils with dense vegetation & 6.0 & 152 \\
Dry loam soils with dense vegetation & 2.0 & 51 \\
Dry clay soils with dense vegetation & 1.7 & 43 \\
Moist sandy soils with little or no vegetation & 1.0 & 25 \\
Moist loam soils with little or no vegetation & 0.3 & 7.6 \\
Moist clay soils with little or no vegetation & 3.3 & 84 \\
Moist sandy soils with dense vegetation & 2.0 & 5.1 \\
Moist loam soils with dense vegetation & 0.7 & 18 \\
Moist clay soils with dense or no vegetation & Minimum (Asymptotic) \\
\hline & Infiltration Capacity, Fc \\
\hline Clay loam, silty clay loam, sandy clay, silty clay, clay & $0.00-0.05$ & $0.00-1.3$ \\
Sandy clay loam & $0.05-0.15$ & $1.3-3.8$ \\
Silt loam, loam & $0.15-0.30$ & $3.8-7.6$ \\
Sand, loamy sand, sandy loam & $0.30-0.45$ & $7.6-11.4$ \\
\hline
\end{tabular}

The calibrated infiltration parameters of maximum/minimum infiltration rates and decay constants were limited to $\pm 40 \%$ of the original estimate. The large diversity in soil types observed in the field led to the assumption that this approach would keep infiltration parameter values within a reasonable range. The ranges of values for soil property parameters are shown in Table 3.

Table 3 Range of subcatchment properties for site specific soil types.

\begin{tabular}{lcccccccc}
\hline \multirow{2}{*}{ Soil Type } & \multicolumn{2}{c}{ fo } & \multicolumn{2}{c}{ fc } & \multicolumn{2}{c}{ DC } & \multicolumn{2}{c}{ DT } \\
& Min. & Max. & Min. & Max. & Min. & Max. & Min. & Max. \\
\hline KMA & 127 & 254 & 7.6 & 11.4 & 2 & 7 & 2 & 14 \\
TSE & 76 & 254 & 3.8 & 7.6 & 2 & 7 & 2 & 14 \\
HnD2 & 51 & 152 & 0.0 & 1.3 & 2 & 7 & 2 & 14 \\
\hline Where: fo = Maximum Infiltration Rate (mm/h); fc= Final/Minimum Infiltration Rate $(\mathrm{mm} / \mathrm{h}) ;$ \\
DC= Decay Constant (1/h); DT= Drying Time (days).
\end{tabular}

As presented later in section 4, after multiple attempts using the SWMM model without the aquifer compartment, calibration efforts did not result in a good agreement between modeled and observed flows in the streams. At this point the other SWMM models using a groundwater module were created with the goal of improving these comparisons. More calibration parameters were introduced with respect to the groundwater component. These parameters were bottom groundwater elevation, saturated hydraulic conductivity, field capacity and conductivity slope. The range of tested values for calibration parameters is presented in Table 4 (Rossman 2005). No changes were implemented in the calibrated values for subcatchment inputs with the introduction of the groundwater components.

Table 4 Aquifer properties for various soil types.

\begin{tabular}{|l|c|c|c|c|}
\hline Soil Texture Class & $\begin{array}{c}\text { Hydraulic } \\
\text { Conductivity } \\
\text { (mm/hr) }\end{array}$ & Porosity & $\begin{array}{c}\text { Field } \\
\text { Capacity }\end{array}$ & $\begin{array}{c}\text { Wilting } \\
\text { Point }\end{array}$ \\
\hline Sand & 120.4 & 0.437 & 0.062 & 0.024 \\
\hline Loamy Sand & 29.97 & 0.437 & 0.105 & 0.047 \\
\hline Sandy Loam & 10.92 & 0.453 & 0.19 & 0.085 \\
\hline Loam & 3.30 & 0.463 & 0.232 & 0.116 \\
\hline Silt Loam & 6.60 & 0.501 & 0.284 & 0.135 \\
\hline Sandy Clay Loam & 1.52 & 0.398 & 0.244 & 0.136 \\
\hline Clay Loam & 1.02 & 0.464 & 0.31 & 0.187 \\
\hline Silty Clay Loam & 1.02 & 0.471 & 0.342 & 0.21 \\
\hline Sandy Clay & 0.508 & 0.43 & 0.321 & 0.221 \\
\hline Silty Clay & 0.508 & 0.479 & 0.371 & 0.251 \\
\hline Clay & 0.254 & 0.475 & 0.378 & 0.635 \\
\hline
\end{tabular}

During calibration involving aquifer components the SRTC was not able to handle the values of bottom groundwater elevation, so a series of trial and errors had to be performed for each individual aquifer component. The lack of field data with respect to the location of the aquifer bottom and the variability of site conditions rendered this value somewhat arbitrary. The designer must use personal judgment to remedy each component's depth. PCSWMM sets a default value of 10 for the conductivity slope. During calibration slight tuning of this value provided a better fit between observed and computed hydrograph recession periods. Lastly, the saturated hydraulic conductivity and field capacity were key components in shaping the outflow produced from the aquifer components. Ranges of these two parameters were developed based on soil types and texture classes and are presented in Table 5. First, input values were based on average values in order to provide a comprehensive description of the AOI. SRTC was used with percent rankings limited to $\pm 40 \%$ and below to ensure results would fall within the prescribed ranges. After the fine tuning of input values, results across the entire spectrum became much more satisfactory with the introduction of the aquifer component in the SWMM models.

Table 5 Range of calibrated aquifer properties for site specific soil types.

\begin{tabular}{lcccccccc}
\hline Soil Type & \multicolumn{2}{c}{$K$} & \multicolumn{2}{c}{$\varphi$} & \multicolumn{2}{c}{$F C$} & \multicolumn{2}{c}{ WP } \\
& Min & Max & Min & Max & Min & Max & Min & Max \\
KMA & 10.92 & 120.4 & 0.437 & 0.453 & 0.062 & 0.19 & 0.024 & 0.085 \\
TSE & 6.6 & 29.7 & 0.453 & 0.501 & 0.232 & 0.284 & 0.085 & 0.135 \\
HnD2 & 0.254 & 1.52 & 0.398 & 0.475 & 0.244 & 0.378 & 0.136 & 0.635 \\
\hline
\end{tabular}

Where $K=$ Saturated Hydraulic Conductivity $(\mathrm{mm} / \mathrm{h}) ; \varphi=$ Porosity; FC= Field capacity; WP $=$ Wilting Point. 
Since there were few rain events that have generated significant runoff episodes, the process of verification of the calibration efforts is still in its initial phase. As an attempt to perform verification of the calibration efforts, comparison between observed and modelled runoff for the rectangular weir was performed for selected rain events.

\section{Results and Discussion}

\subsection{Flow Duration Curves}

Throughout simulation and calibration efforts, flow duration exceedance curves were referenced to confirm that simulation results were conforming to field observations. Figure 5 presents the flow duration curves of two out of the three SWMM models. At the top of Figure 5 the condition where the aquifer component was disabled is displayed, and at the bottom the results with the multi-aquifer configuration is presented. Results with a single aquifer are not presented for brevity but are very similar to the multi-aquifer results.
Results from the model without aquifer indicate that the computed duration curve matches moderately well for flow rates $>1 \mathrm{~m}^{3} / \mathrm{s}$ but then quickly drops off as flows begin to decrease. This characteristic represents the inability to model conditions of interflow and longer recessions curves during the wet season, without the aquifer component. When multiple aquifers were constructed to collect infiltration from subcatchments, the discharge was allowed to route to nodes throughout the channel. The lower chart of Figure 5 shows the effectiveness of the groundwater outflow to increase channel flow at larger flow rates as well as maintain the interflow that is represented by the lower flow rates. Under this aquifer configuration the model has represented flow condition over the broad spectrum very well from $0.3 \mathrm{~m}^{3} / \mathrm{s}$ to $0.01 \mathrm{~m}^{3} / \mathrm{s}$.

\subsection{Modeled Hydrographs Across Dry and Wet Seasons}

This section presents the typical hydrograph results obtained at the Cipolletti weir following the process of calibration using PCSWMM. It also presents the comparisons of the SWMM models
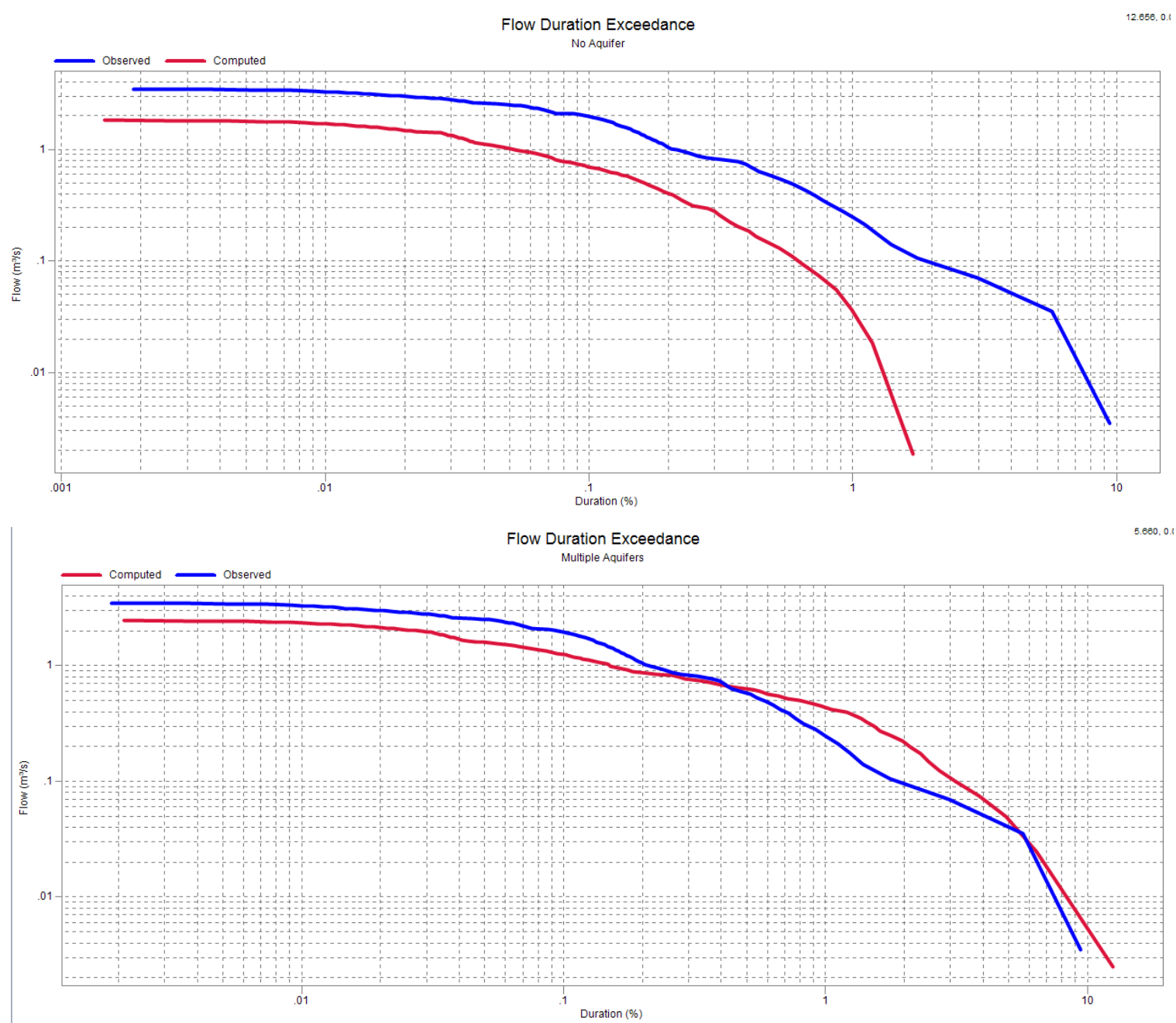

Figure 5 Flow duration curves for WS-AGC with and without aquifer components. 
run with and without the aquifer component. In order to perform this comparison, two rain events that resulted in stream flows were selected, one in the dry season and the other in the wet season.

Figure 6 presents results for these two events for the SWMM model without the aquifer component. Notice that there is a good agreement between the observed (blue line) and modeled (red line) hydrographs measured in the dry season displayed in the top chart. The rain event has medium intensity (at moments $>23 \mathrm{~mm} / \mathrm{h}$ ) and generated a hydrograph peaking at $0.64 \mathrm{~m}^{3} / \mathrm{s}$. The modeled peak is somewhat larger $\left(0.76 \mathrm{~m}^{3} / \mathrm{s}\right)$ and has smaller lag. However, the modeled results obtained with a lower intensity rain event $(<9 \mathrm{~mm} / \mathrm{h})$ in the wet season failed to present any outflow hydrograph, whereas the observed peak flow for that event reached $1.0 \mathrm{~m}^{3} / \mathrm{s}$. This clearly indicated the limitation of the SWMM model without the aquifer component.
Results from these two rain events for the SWMM models using the aquifer component are presented in Figure 7. As explained, there was no change in the subcatchment infiltration parameters with the introduction of aquifer components, and as consequence the top chart in Figure 7 presents the results for the SWMM models using single and the multiple aquifers. They are indistinguishable between themselves and the no aquifer hydrograph.

Results for the rain event in the wet season, on the other hand, are very different and peak flows are much closer to the one measured in the field. The single aquifer modeling alternative is presented in the middle chart in Figure 7 and presents a peak value that approaches better the measured one when compared to the multi-aquifer solution. Both SWMM models with aquifer presented results that have an earlier hydrograph flow rise and delayed recession limb when compared to the modeled results.
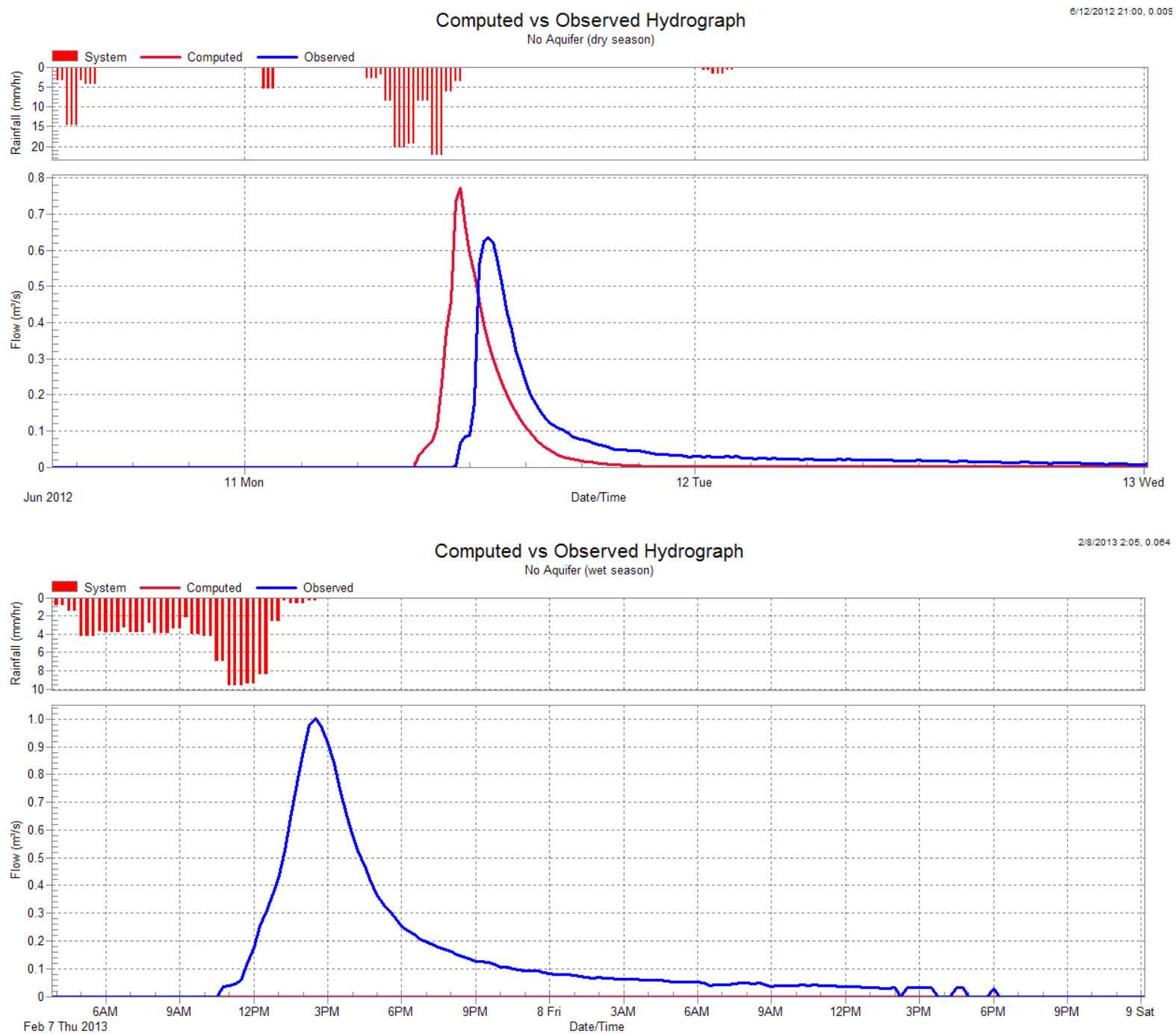

Figure 6 Dry and wet season comparison of computed vs observed hydrographs at the site of the Cipolletti weir with no aquifer component. 

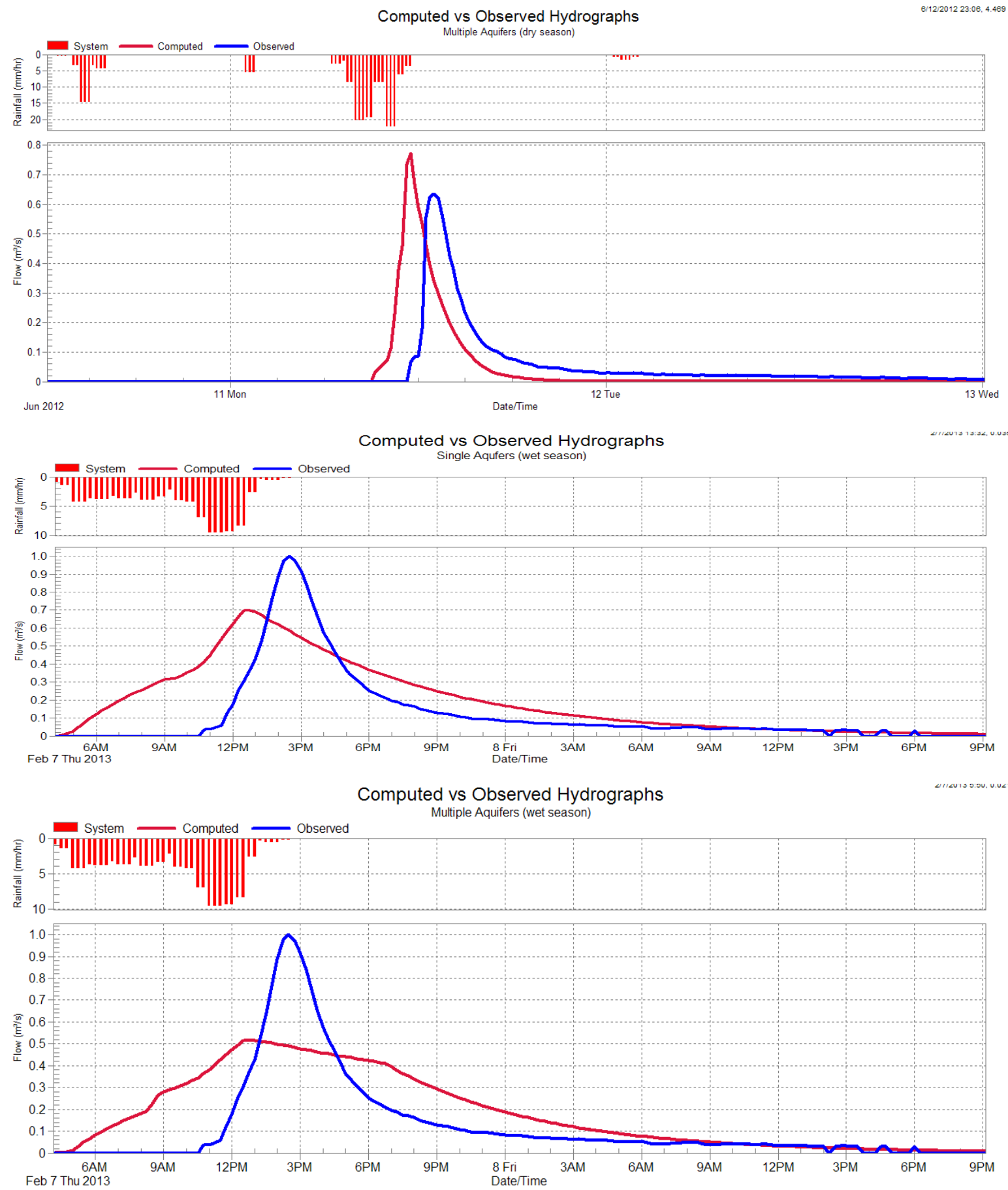

Figure 7 Dry and wet season comparison of computed vs observed hydrographs at the site of the Cipolletti weir with single (centre) and multiple (bottom) aquifer components.

As a means for verification of the calibrated values, considering the small number of rain events available for the calibration effort, it was decided to perform a comparison between measured and predicted flow hydrographs for the rectangular weir, which is located upstream from the Cipolletti weir. Hydrograph results for a rain event during the dry season in this intermediate weir are shown in the top of Figure 8, whereas hydrograph

comparisons for the rain event during the wet season are presented in the bottom of Figure 8 . The dry season rain event selected was in September 2012 because the installation of the rectangular weir in the study site was performed in August 2012. Though calibration efforts did not consider results at this weir, one notices reasonably good agreement between measured and modeled hydrographs. A comparison of this type is not possible 
for the SWMM models with the no aquifer configuration as well as the one aquifer configuration. This is due to the fact that neither one of the two configurations would allow exfiltration during wet season rain events at the location of the rectangular weir, resulting in zero flow experienced in the models.

\subsection{Error Analysis}

Each model configuration was evaluated on its performance to model three conditions. First, the maximum flow rate from each observed event was compared with the maximum flow rate of the computed events. In Table 6 the errors associated with each show that none of the three configurations accurately simulates peak flow rates. This is probably associated with the complexities between seasonal variations.

When the model was adjusted for events during the dry season the infiltration parameters proved to be the most effective. As the calibration then continued through the wet season, these increases in infiltration rates led to results of peak flow rates lower than observed. The aquifer component assisted this deficiency by allowing the lost infiltration water to recharge and increase the peaks during this period. This caused a significant rise of the coefficient of determination $\mathrm{R} 2$, but it was not able to meet many of the events thus resulting in an unsatisfactory result for peak flows.

Table 6 Error analysis between computed and observed variables at downstream Cipoletti weir.

\begin{tabular}{lcccccccccc}
\hline $\begin{array}{l}\text { Model } \\
\text { Config- }\end{array}$ & \multicolumn{3}{c}{ Max Flow $\left(\mathrm{m}^{3} / \mathrm{s}\right)$} & \multicolumn{3}{c}{ Mean Flow $\left(\mathrm{m}^{3} / \mathrm{s}\right)$} & \multicolumn{3}{c}{ Total Volume $\left(\mathrm{m}^{3}\right)$} \\
$\begin{array}{l}\text { uration } \\
\text { No }\end{array}$ & $R^{2}$ & LSE dim & $\begin{array}{c}\text { RMSE } \\
\operatorname{dim}\end{array}$ & $R^{2}$ & LSE dim & $\begin{array}{c}\text { RMSE } \\
\operatorname{dim}\end{array}$ & $R^{2}$ & LSE dim & $\begin{array}{c}\text { RMSE } \\
\operatorname{dim}\end{array}$ \\
$\begin{array}{l}\text { Aquifer } \\
\text { Multiple }\end{array}$ & 0.011 & 4.630 & 1.000 & 0.166 & 5.250 & 1.210 & 0.232 & 5.250 & 1.330 \\
$\begin{array}{l}\text { Aquifer } \\
\text { Single }\end{array}$ & 0.397 & 4.150 & 0.780 & 0.899 & 20.900 & 0.420 & 0.975 & 20.900 & 0.237 \\
Aquifer & 0.383 & 5.780 & 0.788 & 0.888 & 26.500 & 0.443 & 0.986 & 26.500 & 0.179 \\
\hline
\end{tabular}

When the model was adjusted for events during the dry season the infiltration parameters proved to be the most
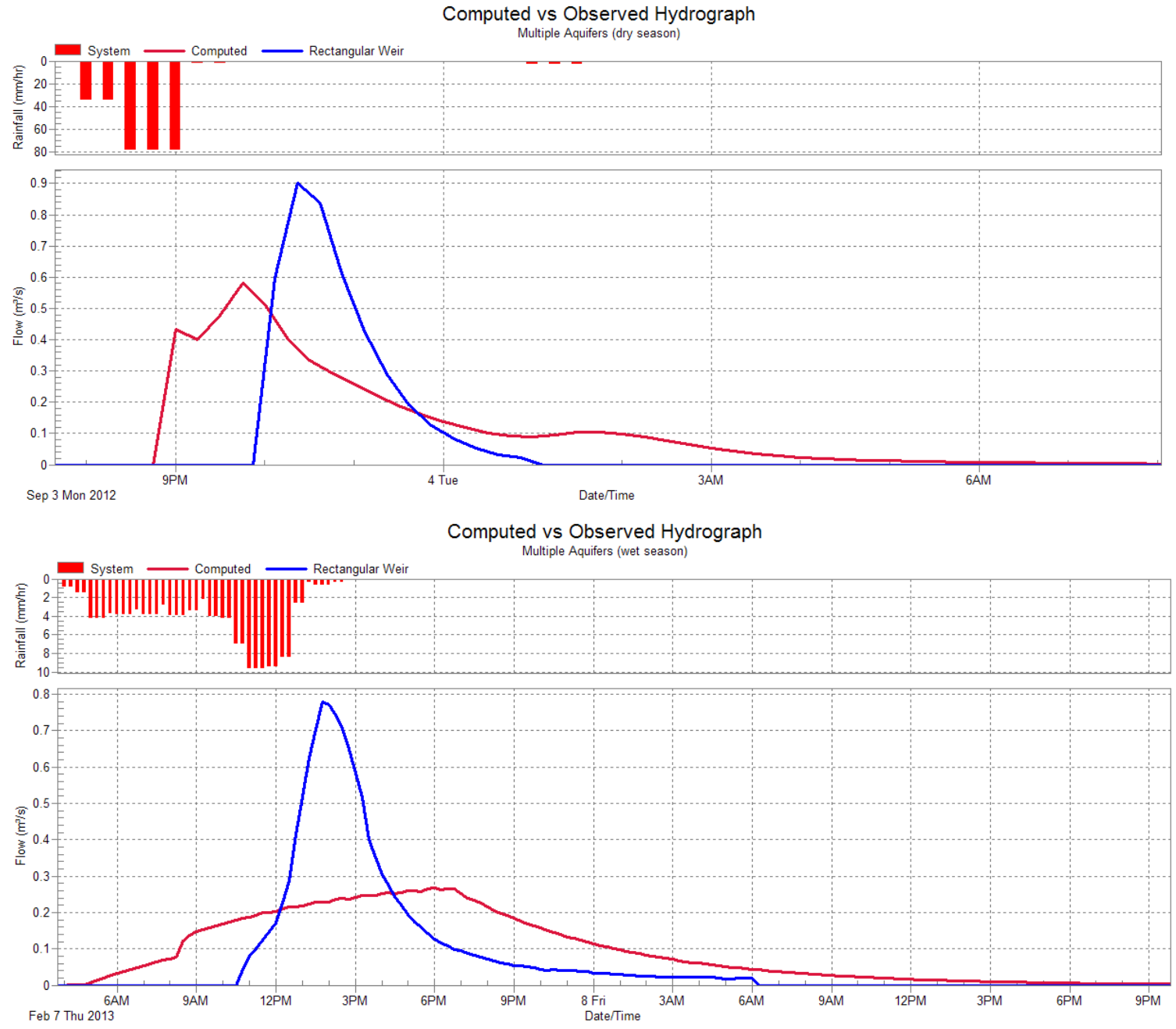

Figure 8 Dry and wet season comparison of computed vs observed hydrographs at the site of the rectangular weir with multiple aquifer components. 
effective. As the calibration then continued through the wet season, these increases in infiltration rates led to results of peak flow rates lower than observed. The aquifer component assisted this deficiency by allowing the lost infiltration water to recharge and increase the peaks during this period. This caused a significant rise of the coefficient of determination $R^{2}$, but it was not able to meet many of the events thus resulting in an unsatisfactory result for peak flows.

Continuing to evaluate the three configurations performance, the mean flow rate $\left(\mathrm{m}^{3} / \mathrm{s}\right)$ was evaluated. Table 6 shows that $R^{2}$ values for the aquifer configurations were once again much higher. This is representative of the aquifers ability to model the interflow occurring during the wet season. Finally, the total volume from each event was analyzed. This component of the analysis provides the best correlations with $R^{2}$ values for the two aquifer configurations close to 1 .

The result from the total volume analysis provides confidence in the ability of the model to replicate the most important factor for our needs. Since we are developing this model to be used to predict the feasibility of a future pond to sustain water, volumes observed in the site must be as accurate as possible.

\section{Summary and Future Work}

This paper has presented the preliminary results of an ongoing investigation of the hydrological characteristics of a rural and intermittent watershed located in the Lower Coastal Plain region of the United States. This work has focused on the use of SWMM modelling as a means to describe the various interactions between the hydrological compartments that were observed in the field investigation. These included the relationship between rainfall, infiltration, runoff and exfiltration from groundwater into the intermittent stream.

Following calibration efforts using the SRTC tool from PCSWMM, the model without aquifer was effective only in the reproduction of a surface hydrograph of a medium intensity rain, but not runoffs observed in wet season rain events. Results clearly indicate the importance of incorporating aquifer component in a SWMM model so that low intensity rain events occurring in the wet season can effectively result in surface runoff. Alternatives with one and with multi-aquifer components were fairly effective in reproducing the total volume of rain events, but the shape of the hydrograph in wet weather flows is generally more abated than what was measured. One speculates that the limitation in the description of the infiltration mechanisms for the various soils in the area and the actual accuracy of the soil survey can be causes for the discrepancy in observed results.

However, results confirm that SWMM models with the aquifer components enabled produced satisfactory results with regards to overall flow volumes and the observed flow duration curve. While improvements will still be implemented in the near future, it is believed that this model will have fair to good accuracy in long term simulations of the research watershed. Such simulations will help with the development of local water resources, providing a useful tool to meet the objectives of AGC/AL.

\section{Acknowledgments}

The authors would like to acknowledge the instrumental support provided by the Alabama chapter of the Associated General Contractors of America; by Auburn University which has funded part of this research; and by $\mathrm{CHI}$ which provided a grant that allowed the authors to use PCSWMM in their simulations.

\section{References}

Akan, A. O. 1993. Urban Stormwater Hydrology: A Guide to Engineering Calculations. Lancaster, PA: Technomic.

Amatya D. M., C. Harrison and C. C. Trettin. 2007. “Water Quality of Two First Order Forested Watersheds in Coastal South Carolina." In Proceedings of the Fourth Conference on Watershed Management to Meet Water Quality and TMDL Issues: Solutions and Impediments to Watershed Management and TMDLs, San Antonio, Texas, edited by A. McFarland and A. Saleh. St Joseph, MI: American Society of Agricultural and Biological Engineers. ASABE Publication 701P0207.

Bizier, P. 2007. Gravity Sanitary Sewer Design and Construction. Reston, VA: American Society of Civil Engineers.

Czikowsky, M. J. and D. R. Fitzjarrald. 2004. "Evidence of Seasonal Changes in Evapotranspiration in Eastern United States Hydrological Records." Journal of Hydrometeorology 5 (5): 974-88.

Davis, J. P., C. A. Rohrer and L. A. Roesner. 2007. "Calibration of Rural Watershed Models in the North Carolina Piedmont Ecoregion." In Proceedings of the 2007 World Environmental and Water Resources Congress: Restoring Our Natural Habitat, edited by K. C. Kabbes. Reston, VA: American Society of Civil Engineers.

Dodge, R. 2001. "Weirs." Chap. 7 in A Guide to Effective Water Measurement Practices for Better Water Management, 3rd ed. Washington, DC: U.S. Government Printing Office

Harder, S. V., D. M. Amatya, T. J. Callahan, C. C. Trettin and J. Hakkila. 2007. “Hydrology and Water Budget for a Forested Atlantic Coastal Plain Watershed, South Carolina." Journal of the American Water Resources Association, 43 (3): 563-75.

James, W. R. C., B. Wan and W. James. 2002. "Implementation in PCSWMM Using Genetic Algorithms for Auto-Calibration and Design Optimization". In Proceedings of the 9th International Conference on Urban Drainage: Global Solutions for Urban Drainage, 1-10. Reston, VA: American Society of Civil Engineers. doi:10.1061/40644(2002)90.

La Torre Torres, I. B., D. M. Amatya, G. Sun and T. J. Callahan. 2011. "Seasonal Rainfall-Runoff Relationships in a Lowland Forested Watershed in the Southeastern U.S.A." Hydrological Processes. doi:10.1002/hyp.7955. 
McCuen, R. H., P. A. Johnson and R. M. Ragan. 1996. Highway Hydrology, 2nd edn. Hydraulic Design Series No. 2. Washington, DC. Federal Highway Administration. Report FHWASA-067.

Nagy R. C., B. G. Lockaby, B. Helms, L. Kalin and D. Stoeckel. 2011. "Water Resources and Land Use and Cover in a Humid Region: The Southeastern United States." Journal of Environmental Quality, 40 (3): 867-78.

Rossman, L. 2005. Storm Water Management Model User's Manual (Version 5.0). Washington, DC: U.S. Environmental Protection Agency.

Kyle P. Moynihan Auburn University, Auburn, AL.

José G. Vasconcelos Auburn University, Auburn, AL.
Sun G., S. McNulty, D. Amatya, R. Skaggs , L. Swift Jr, J. Shepard and H. Riekerk. 2002. "A Comparison of the Watershed Hydrology of Coastal Forested Wetlands and the Mountainous Uplands in the Southern United States." Journal of Hydrology, 263:92-104.

Sun G., A. Noormets, M. J. Gavazzil, S. G. McNulty, J. Chen, J.-C. Domec, J. S. King, D. M. Amatya and R. W. Skaggs. 2010. "Energy and Water Balance of Two Contrasting Loblolly Pine Plantations on the Lower Coastal Plain of North Carolina, United States." Forest Ecology and Management, 259:1299-1310. 